\title{
Impact of Intrinsic Factors and Subjective Norms that Influence Purchase Intention in Sri Lankan Online Retail Apparel Industry
}

\author{
A. C. De Silva ${ }^{1}$ and H. M. A. Herath ${ }^{2}$ \\ 1,2 Department of Business Management, Wayamba University of Sri Lanka, \\ Kuliyapitiya, (60200), Sri Lanka. \\ 1desilvamanda@gmail.com, ${ }^{2}$ hemuherath@gmail.com
}

\begin{abstract}
Throughout the past decade, the development of the internet as a marketing tool has become a worldwide trend. In the apparel industry, the online platform has become a fertile ground for direct marketing resulting in the disintermediation of number of intermediaries in the traditional marketing channel. Compared to other developed countries, the habit of purchasing through digital market by Sri Lankan customers is obviously at a lower level. Moreover, even at the global level, there are few studies over purchasing of apparel online while scholars have emphasized the necessity of more studies in different contexts. In the Sri Lankan context, there is a lacuna of the empirical evidence in the area. The focus of this study is to identify and investigate the major factors that influence online purchasing intention among Sri Lankan online buyers. Therein, based on a comprehensive literature review, four factors were identified under the categories of subjective norms and intrinsic factors. A field survey was conducted to investigate the effect of perceived value, perceived risk, and perceived quality and peer pressure on online purchasing intention. The primary data was collected by means of a structured questionnaire and interviews from a sample of 384 customers selected on the simple random basis. The model was tested by using the simple regression analysis and the results revealed that perceived value, perceived quality and peer pressure show a positive effect on the online retail apparel purchasing intention among customers. The study also found that there are many research avenues for invigorating the scientific body of knowledge in this area.
\end{abstract}

Keywords: Intention to purchase, Online retail apparel, Perceived value, Perceived quality, Peer pressure

\section{Introduction}

The advancement in technology and the internet has made communication easy and fast for people around the globe. Someone from one end of the globe is now able to communicate with another who lives in the other end of the world showing how far technology has developed over the recent past. With the Internet becoming an integral part of a common person's everyday life today social media networks play a significant role in the personal life as well as the business world by disintermediation in creating an avenue for direct contacts between marketers and consumers. Digital marketing and marketing through social media are common Marketing concepts that are pursued by many businesses today irrespective of the size of the firm. Social Media platforms offer businesspersons a new and convenient mode of tapping into the target market, which is more efficient than the 
traditional market. This also enables better interactions with customers and potential customers of the target market. Social media and the internet has become a platform that increases the brand and product awareness among people around the world. As far as the Sri Lankan Social media usage is concerned, Internet usage has grown at a significant rate from $20 \%$ to $25 \%$ every year, during the last 5 to 6 years in Sri Lanka where there are more than 6 million active internet users. It is also proven that $63 \%$ of all Sri Lankan internet visits happen on a mobile device (Jain, 2018). According to the Stat counter, Facebook is the most reachable media among other Social Media market in Sri Lanka, which is $80.67 \%$ (GlobalStats, 2020). According to (Rahman, Islam, Esha, Sultana, \& Chakravorty, 2018), online shopping in Bangladesh has been evolving fast and has the potential to grow exponentially. By the end of 2019, according to Statista the global e-commerce market, had sales reaching 3.5 billion dollars and represented $14 \%$ of the total share of global retail sales (Susan Meyer, 2020).

In the Sri Lankan context, the retail apparel market is prominent among the conversations around the country. This is because people have the intention of seeking and being updated with the current fashion trends. In Sri Lanka, the retail sector in apparel reports a quick development. Nevertheless, its market share is still at a lower level compared to other developed countries. In this industry, fashion-wear retailing represents a large portion of $(39 \%)$ showing a great possibility to develop in future (Jayasuriya, Azam, \& Ferdous, 2017). Today retail businesses have expanded into social media platforms to exploit the opportunities available in the growing digital market. However, with this growing trend, the empirical evidences are essential to prove the main factors that are pivotal for marketers to attract more and more customers.

Even though many studies have been done in the e-commerce and technology acceptance, and there is a dearth of research on how website content affect purchase intention. Thus, it is important to investigate the other factors influencing the purchase intention of the Sri Lankan customers in the online shopping environment, since there is a lacuna in the body of knowledge in South Asian countries. Moreover, according to the research conducted by Athapaththu \& Kulathunga, (2018) on factors affecting online purchase intention in Sri Lankan context and found that Sri Lankan traditional consumer process in switching from traditional physical markets to the digital platform is at a lower rate compared to other countries. Obviously, there is a need for more studies in the field of online shopping. In the Sri Lankan context, the prominent researchers that fall to this category are the researches carried out by Herath \& Wijesundara, (2008) where the researcher had investigated the factors affecting online shopping. Also the research done by Athapaththu \& Kulathunga, (2018) tested the online purchase intention to determine the relationships between those identified factors and online purchase intention of retail shopping in Sri Lanka by only using four dimensions (Perceived Usefulness, Perceived Ease of Use, Website Content and Trust of the scale (Davis, 1986). Further, (Karunanayake \& Madubashini, 2019) identified the influence of user-generated content on 
purchase intention of automobiles in Sri Lanka.

\section{Literature Review}

A review of literature reveals that though an empirical study by Karunanayake \& Wanninayake, (2015) were done on determinants on purchase intention of Hybrid Vehicle Brands in Sri Lanka, one of the key determinants taken into consideration was subjective norms but not the impact of intrinsic factors and subjective norms with regards to online retail apparel on purchase intention from a business perspective. Karunanayake $\&$ Wanninayake, (2015) is the closest study that looks into subjective norms in the Sri Lankan context. Consequently, it is timely requirement to investigate the factors influencing online purchase intention in online retail shopping since the businesses have moved mainly towards online retail shopping (Ahmad \& Khan, 2015). Sri Lankan fashion retail sector is creating an environment for retailers where growth and success are within the forefront. However, few research studies have been done so far to assess different issues involved in the industry (Ranaweera \& Halwatura, 2014).

Out of many industries that have flared up on social media, apparel and fashion retail are two of the most outspoken industries especially on Facebook. As consumers already spend a considerable amount of time on these platforms, businesses only have to establish a strong presence, which could be heard and felt by consumers (Kitzinger \& Mandelbaum, 2013). Today, digital retail consumers may be driven by recommendations and persuasive communication on the online platform.
Accordingly, it compels researchers to prove empirically by investigating the factors to make consumers' purchase decisions. Consequently, the retail industry can be considered as one of the greatly influenced areas of the modern business world. However, in the Sri Lankan context, there are no sufficient empirical studies to understand the impact of intrinsic factors and subjective norms on purchase intention in the online retail apparel industry. The research model of this study has been constructed to fill the prevailing vacuum by addressing the main research problem, "What is the impact of Intrinsic factors and subjective norms on the purchasing intention of retail apparel online by Sri Lankan consumers"? Therefore, the study aims to achieve the following objectives derived from the research problem. To examine the level of impact of intrinsic factors and subjective norms on the purchasing intention in Sri Lankan online retail apparel industry. Under subjective norms, the impact of peer pressure was studied as an independent variable while the impact of perceived value, perceived risk and perceived quality were investigated under the category of intrinsic factors.

Purchase intention (PI) generally refers to the consumers' intention to buy a product and service. According to (Fishbein \& Ajzen, 1976), purchase intention of the customer stimulates profits to the business industry, particularly when customers are satisfied with what the business offers. On the other hand, purchasing intention means the degree of perceptual conviction of a customer to purchase a certain product or service. Previous researchers had identified that both product or service quality and the purchase intention reports 
a positive relationship. For developing purchase intention model, it is important to identify factors, which affect the purchase intention of the customers.

Previous empirical studies have shown that perceived value is an important factor in customer's purchasing of product or service. To understand the consumer perceived value of casual sportswear, (Chi \& Kilduff, 2011) assessed empirically by using the consumer perceived value (CVP) model and the model was proven valid. A similar study was carried out by Jaafar, Lalp, \& Naba 2012 to investigate onsumers' perceptions, attitudes and purchase intention towards private label food products in Malaysia). Another study on mobile value added services showed that the perceived value positively influences on post purchase intention (Kuo, Wu, \& Deng, 2009). A study conducted for investigating the potential mediating effect of perceived value on the relationship between team identification and intent to purchase collegiate team-licensed apparel concluded that it is important to consider perceived value.

To assess the effect of these factors an online purchasing perspective the research model in the Figure 1 was developed.

Directly derived from the research model, four hypotheses were tested in this study. The $\mathrm{H} 1$ is that, there is a positive impact of perceived value on purchase intention in online retail apparel industry in Sri Lanka.

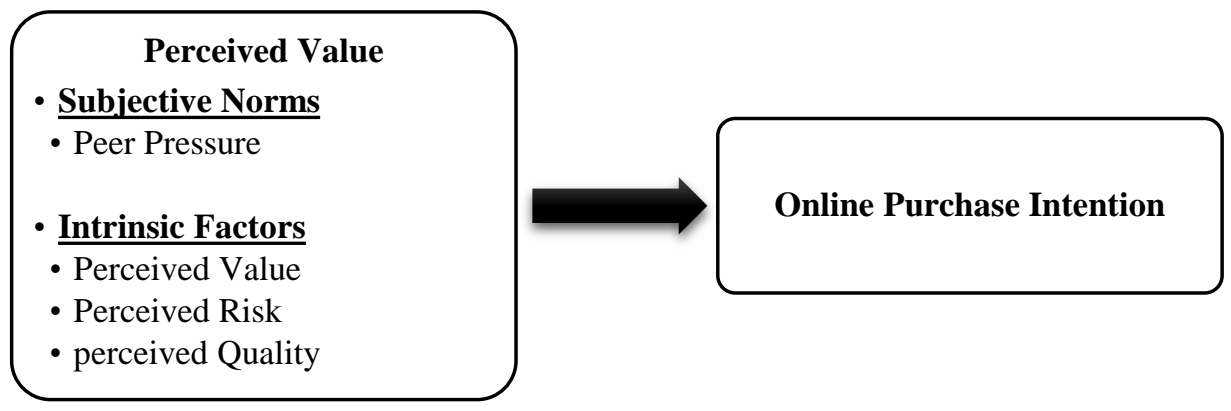

Figure 01: Conceptual Framework

Source: Authors, 2020

The theory of perceived risk has been used to explain customers' behaviour. Bauer is the first to develop perceived risk based on psychology theory. According to Bauer, customers' behaviour involved risk because their purchasing actions "will produce consequences which he cannot anticipate with anything approximating certainty, and some of which at least are likely to be unpleasant'. (Cox, 1967) proposed the perception that customer get from the buying action is related to "Financial" or "Social-psychological". Previous studies showed that the perceived risk and purchase intentions have a negative 
causality with trust, meaning that if enterprises wish to increase consumers' purchase intentions; they should lower products' perceived risk and increase confidence in the products (Chen, Tsai, $\&$ Hsieh, 2017). To investigate this from an online purchasing perspective the $\mathrm{H} 2$ was developed as, there is a negative impact between customer's perceived risk and purchasing intention on online retail apparel industry in Sri Lanka.

The perceived quality can be the customer's overall perception and acknowledgement of a product offered by marketer to the customer. (Mitra \& Golder, 2006), describes perceived quality as perception of the customer. According to (Zeithaml, 1988), perceived quality is defined as a subjective customer's judgment regarding the overall product superiority. According to (Jaafar, Lalp, \& Naba, 2012), consumers always think that purchasing a low price, simple packaging and even less-well known product are highly risky because the quality of those products are lacking the confidence and it is doubtful. However, the study conducted by (Jaafar, Lalp, \& Naba, 2012) showed that the relationship between perceived quality and purchase intention has a low, definite but small correlation. To investigate perceived quality from an online purchasing perspective the hypothesis H3 was developed as follows. There is a positive impact of perceived quality on purchase intention in the online retail apparel industry in Sri Lanka.

The opinion of friends and family tends to influence the online purchasing decisions of individuals. Previous empirical studies have shown that teenagers and youngsters are usually vulnerable to peer pressure and have high tendency to make decisions and develop behaviors which positively comply with the peer's expectations. For a study conducted in Botswana researchers found that the impact of peer pressure on purchase intention is quite significant, (Makgosa \& Mohube, 2007). However, a study carried out by (Samit \&Cazacu, 2016) on private label products in Thessaloniki, in the context of economic crisis found that people showed a neutral level of concern about the opinions of the other people. To test this relationship further in the context of the Sri Lankan retail apparel industry, the study tested the hypothesis $\mathrm{H} 4$ as; there is a positive impact of peer pressure on purchase intention in online retail apparel industry in Sri Lanka.

Based on the available body of knowledge by comprehensive literature review, the conceptual framework in Figure 1 has been developed in order to show a clear pathway for the research study.

\section{Research Methodology}

As this is a quantitative study, the research instrument is a structured questionnaire survey. This aims on objective measurement to the study along with statistical data analysis. The research carried out a causal investigation. A causal study is conducted to find out the cause and effect relationship. The study tests whether or not one variable causes another to change (Sekaran \& Bougie, 2016), where the variables are independent and dependent. The study setting is a non- contrived setting, which states that the study is performed with less inference by the researcher. The data was gathered mainly from the Western Province of the country, which includes three districts 
Colombo, Gampaha and Kalutara. Data was gathered through a single time; hence, the time horizon is crosssectional. Based on the data provided by Department of Census and Statistics for 2018 (Statistics, 2018), the three districts in the western-province (Colombo, Kalutara and Gampaha) represents $28 \%$ of the total population of the country making the total as $6,129,000$. There are over 6 million active internet users in the country, with nearly $43 \%$ of the active internet users utilizing e-commerce platforms to purchase goods or services (LIRNEasia, 2020). According to (Krejcie \& Morgan, 1970) when the population is more than 1 million and at the confidence level of $95 \%$ they recommend a sample size of 384 . Thus, the researchers followed the recommendation from Morgan table for this study to select the sample size by using the simple random sampling technique.

A structured questionnaire was distributed among the respondents physically as well as through an online mode. The online mode of questionnaire enabled to reach a wider audience within a limited span of time. The questionnaire consisted with three sections. The section one of the questionnaire consists of five demographic questions where the information was gathered on the gender, age, geographical area, occupation and the monthly income of respondents. Section 2 consisted of four questions on online retail apparel platforms in order to support the primary objective of the research study. Fundamentally, the above-mentioned four questions were raised to get an understanding on the consumer purchase behaviour on online retail apparel among domestic customers. Section 3 consisted of 25 questions under five dimensions. First four dimensions evaluate the independent variable, which is the impact on online retail apparel. Last dimension evaluates the dependent variable, which is about the purchase intention. For each of the variables, predefined indicators were found from literature. These indicators have been previously utilized by researchers in their studies bringing in more relevance, valid and reliable for the current study. Questionnaire of this research study is designed, as able to accomplish the research objectives and able to analyze the variables which covered by the hypotheses. Under this research questionnaire survey implement it includes questions which are using both open ended and close ended to get better understanding of respondents, Likert scale has been used to get the true perceptions of the respondent with strongly disagree to strongly agree and use direct questions. The hypotheses testing was done by using the correlation and regression analysis.

\section{Analysis and Results}

Evidence showed that the reliability and validity tests conducted indicate the measure is consistent and, it is evident that the variables are at satisfactory scores above 0.7. Further, all KMO values for the variables were greater than 0.5 and all P-values of Bartlett's test of sphericity were less than 0.05 . Therefore, the questionnaire is valid, and the study proceeded with the main study and the rest of the analysis.

The filled questionnaire had no missing values which can make a significant effect on final results. Further, it was found that means of respective dimensions are not significantly 
deviating from its respective $5 \%$ trimmed mean. Therefore, no significant outliers were identified. Further, the skewness and kurtosis results fall within the accepted range, thus it can be as concluded that the data for all the variables are normally distributed. Based on results, the strength of the variables falls in the acceptable range. Thus, the study proceeded with the analysis of correlation and regression for the variables concerned.

Table 01: Correlation

\begin{tabular}{|l|c|c|}
\hline & Pearson Coefficient & P Value \\
\hline $\mathrm{PV} \longrightarrow \mathrm{PI}$ & 0.614 & 0.01 \\
\hline $\mathrm{PR} \longrightarrow \mathrm{PI}$ & -0.414 & 0.01 \\
\hline $\mathrm{PQ} \longrightarrow \mathrm{PI}$ & 0.624 & 0.01 \\
\hline $\mathrm{PP} \longrightarrow \mathrm{PI}$ & 0.577 & 0.01 \\
\hline
\end{tabular}

Notes: PV- Perceived Value, PR- Perceived Risk, PQ- Perceived Quality, PP- Peer Pressure, PI-

Purchase Intention

Source: Survey data (2020)

Based on the Pearson's correlation analysis conducted it can be observed that the correlation coefficient of Perceived Value, Perceived Risk and perceived quality indicates a moderate positive relationship with Purchase Intention and it can be observed that perceived risk has a moderate negative relationship. The $\mathrm{p}$ value is 0.01 , which indicates the correlation is confident at 99\%. Hence, the results obtained in the correlation analysis conducted can be validated and $\mathrm{H} 1, \mathrm{H} 2, \mathrm{H} 3, \mathrm{H} 4$ can be accepted.

Table 02: Simple Regression - Model Summary

\begin{tabular}{|l|c|c|c|c|c|}
\hline Hypothesis & R & R Square & $\begin{array}{c}\text { Adjusted } \\
\text { R square }\end{array}$ & $\begin{array}{c}\text { Std. Error of } \\
\text { the Estimate }\end{array}$ & Sig \\
\hline $\mathrm{H}_{1}$ Model Summary & $.614^{\mathrm{a}}$ & .376 & .370 & .577 & $.000^{\mathrm{b}}$ \\
\hline $\mathrm{H}_{2}$ Model Summary & $.414^{\mathrm{a}}$ & .171 & .169 & .456 & $.000^{\mathrm{b}}$ \\
\hline $\mathrm{H}_{3}$ Model Summary & $.624^{\mathrm{a}}$ & .389 & .383 & .571 & $.000^{\mathrm{b}}$ \\
\hline $\mathrm{H}_{4}$ Model Summary & $.577^{\mathrm{a}}$ & .333 & .326 & .597 & $.001^{\mathrm{b}}$ \\
\hline
\end{tabular}

Source: Survey data (2020)

The results fully agree to accept the hypothesis since the sig value is less than the p-value of $.05 \%$, which indicates perceived value, perceived quality and peer pressure do have a positive and significant impact on the purchase intention of customers. Thus, $\mathrm{H} 1, \mathrm{H} 3, \mathrm{H} 4$ have a positive impact on purchase intention. Perceived risk factors have a negative and significant impact on the purchase intention of customers. Therefore, H2, shows a negative impact of perceived risk on purchase intention in online retail apparel industry in Sri Lanka is supported. 


\section{Discussion}

The findings of the study provide valuable insights for web/online retailers as well as Facebook based website designers since Facebook is the most popular social media platform being the second most visited website in the world and number one in Sri Lanka. (Rathnayake \& Rathnayake, 2018). According to the results, it was found that the perceived quality and perceived value are the key factors that customers consider in the online purchase of retail apparel considering the overall superiority of the product. This is consistent with researches conducted by (Samit \& CAZACU, 2016); (Jaafar, Lalp, \& Naba, 2012). Further, in examining the relationship between the purchase intention and peer pressure toward online apparel purchasing the results obtained were consistent with those reported by (Makgosa \& Mohube, 2007); (Kalafatis, Pollard, East, \& Tsogas, 1999). However, some results have found exceptions to this relationship (Samit \& CAZACU, 2016).

Since the study has found that perceived, value and perceived quality along with peer pressure are the critical factors affecting online purchase intention. In this context, the researchers have identified that it is necessary for web apparel retailers as well as the Sri Lankan government to include in their goals when they take strategic decisions. Web retailers could employ different mechanisms in order to establish the perceived value and quality that the customers are looking for and consequently attract more customers to the web store. Peer pressure is also one of the key factors affecting online purchase intention and therefore, the web retailers should continuously analyse and respond to the recommendations made by customers online on the business site. In addition, displaying the web content/graphics in an attractive and eye-catching style should also be given special attention. In terms of the theoretical perspective, the present study proposes a new model related to purchase intention, since the traditional framework does not address the variables in the theory of planned behaviour and perceived value \& perceived quality together.

Mainly, a company that sells apparel online should design and optimize its services based on these factors. Specifically, high quality clothes for a reasonable price and suitable packaging will more likely to achieve sustainable competitive advantage for companies over their competitors. Also, the more accurate, relevant and complete information shall likely to attract potential customers and make their mind to purchase. Additionally, the greater the quality and value the greater will be the intention of the clients to proceed to the purchase. Further, according to research findings marketers can be successful in online retail flat forms by concentrating on these variables. Furthermore, it was also found that peer pressure towards online purchase intention on retail apparel has significant effects on individuals' intention to purchase. In online retail apparel context, peer pressure could play critical roles in predicting individuals' intention. Since the opinions of family, friends and other opinion leaders are critical for making the final purchasing decision, 
the online marketers of the retail apparel should create positive attitudes towards their online trading. When such opinions are not positive, they will be reluctant to make a purchase/order. Moreover, the results of the study can be used by the marketers persuade the customer's buying decision as well as crafting marketing strategies. Based on the results, online distributors should improve the image of the apparel they sell, by the use of advanced technologies, such as virtual reality, 3D technology, product video, panorama image or live streaming to display the products. Online reviews are important sources of information and there is a need to continue to invest in platforms that help monitor online reviews, manage online reputation and use guest feedback to improve service and product quality.

Additionally, analysing the customer's patterns of purchasing behaviour and the profile of customers in each segment, marketers shall determine which market segments are relevant for their product or service or even for strategic decisions in the future. Moreover, findings will help online retail business managers to develop appropriate strategies that drive loyalty and enhance intentions to purchase through Online Social Media platforms.

Further, as customers consider some level of perceived risk in the process of purchasing, it will also compel marketers to improve software for strengthening cyber-security measures to lower the perceived risk of the customers. Therefore, purchase decisions with regards to apparel will make an influence the software development industry.

In this study, it showed that some level of perceived risk affects the Sri Lankan customer purchase intention. Therefore, it will greatly help the social media community if the policies and laws are enacted for marketers to be adhered. Such frauds with special reference to the online retail apparel industry could be fake promos, pricing inefficiencies, Inorganic boosts (Paid likes and comments), which will provide wrong information to the buyers need to be controlled. Another option is by monitoring customer grievances, they need to control and monitor these social media activities and there by using fair promotional activities and healthy competition between retailers for enhancing the quality of information, increasing the credibility of the information shared.

\section{Conclusion}

This study provides evidence to the impact of intrinsic factors and subjective norms have on the purchase intention in the online retail apparel industry in Sri Lanka. From the evidence drawn it can be noted that perceived value, perceived quality and peer pressure positively impacts purchase intention and perceived risk negatively impacts purchase intention as mentioned above which is consistent with many other previous research. The author borrowed contrasts from the theory of planned behaviour and the theory of perceived risk to explain the factors affecting purchase intention on online retail apparel.

Contribution from this study from an academic perspective will help the 
future researchers with survey information and findings along with some references to the influence of various variables on online purchase intention on online retail apparel. It is obvious that there are no notable studies conducted on this topic in the
Sri Lankan context. This study can be useful for businesses that are on the verge of establishing a new online retail flat form. Moreover, for the government and policy makers for streamlining the selling and buying process.

\section{References}

Ahmad, A., \& Khan, M. (2015). Mapping Online Buyer Behavior: A Critical Review of Empirical Studies.

Apparel, S. L. (2017). Apparel Manufaturers, Suppliers \& Exporters in Sri Lanka. Retrieved from Srilankabusiness.com: http://www.srilankabusiness.com/apparel/

Athapaththu, J. C., \& Kulathunga, K. M. (2018). Factors Affecting Online Purchase Intention: A Study of Sri Lankan Online Customers.

Chen, H. S., Tsai, B. K., \& Hsieh, C. M. (2017). Determinants of consumers' purchasing intentions for the hydrogen-electric motorcycle. Sustainability, 1447.

Chi, T., \& Kilduff, P. P. (2011). Understanding consumer perceived value of casual sportswear an empirical study. Journal of Retailing and Consumer Services.

Cox, D. F. (1967). Risk taking and information handling in consumer behavior. .

DailyFT. (2013). Trends and shifts in apparel retail, marketing and sourcing. Retrieved from http://www.ft.lk/article/203706/Trends-and-shifts-in-apparelretail--marketing-and-sourcing

Davis, F. D. (1986). A technology acceptance model for empirically testing new enduser information systems: theory and results.

Fishbein, M., \& Ajzen, I. (1976). Misconceptions about the Fishbein model: Reflections on a study by Songer-Nocks. Journal of Experimental Social Psychology, 579-584.

GlobalStats. (2020). Social media Stats Sri Lanka. Retrieved from stat counter Global Stats: https://gs.statcounter.com/social-media-stats/all/sri-lanka

Herath, H., \& Wijesundara, C. B. (2008). Factors affecting online purchase decisions of Sri Lankan consumer: with special reference to Western province.

Jaafar, S. N., Lalp, P. E., \& Naba, M. M. (2012). Consumers' perceptions, attitudes and purchase intention towards private label food products in Malaysia. Asian Journal of Business and Management Sciences, 73-90. 
Jain, S. (2018). 40 Amazing Digital and Social Media Marketing Stats and Facts of Sri Lanka - 2018. Retrieved from Social Media and Digital Marketing Blog: https://www.soravjain.com/digital-and-social-media-marketing-stats-andfacts-of-sri-lanka-2018

Jayasuriya, N. A., Azam, S. F., \& Ferdous, M. (2017). The impact of social media marketing on brand equity: A study of fashion-wear retail in Sri Lanka. International Review of Management and Marketing, 178-183.

Kalafatis, S. P., Pollard, M., East, R., \& Tsogas, M. H. (1999). Green marketing and Ajzen's theory of planned behaviour: a cross-market examination. Journal of consumer marketing, 441-460.

Karunanayake, R. T., \& Wanninayake, W. B. (2015). Impact of key purchasing determinants on purchase intention of hybrid vehicle brands in Sri Lanka, an empirical study.

Karunanayake, T., \& Madubashini, C. (2019). The Influence of User Generated Content on Purchase Intention of Automobiles in Sri Lanka. 15.

Kitzinger, C., \& Mandelbaum, J. (2013). Word selection and social identities in talkin-interaction. Communication Monographs, 176-198.

Krejcie, R. V., \& Morgan, D. W. (1970). Determining sample size for research activities. Educational and psychological measurement.

Kuo, Y. F., Wu, C. M., \& Deng, W. J. (2009). The relationships among service quality, perceived value, customer satisfaction, and post-purchase intention in mobile value-added services. Computers in human behavior.

LIRNEasia. (2020). AfterAccess: ICT access and use in Asia and the Global South.

Makgosa, R., \& Mohube, K. (2007). Peer influence on young adults products purchase decisions. African Journal of Business Management.

Mitra, D., \& Golder, P. N. (2006). How Does Objective Quality Affect Perceived Quality? Short-Term Effects, Long-Term Effects, and Asymmetries. Marketing Science, 230-247.

Rahman, M. A., Islam, M. A., Esha, B. H., Sultana, N., \& Chakravorty, S. (2018). Consumer buying behavior towards online shopping: An empirical study on Dhaka city, Bangladesh. . Cogent Business \& Management.

Ranaweera, H. R., \& Halwatura, R. U. (2014). Analysis of Tourism and Fashion Retailing; A Sri Lankan Perspective. In 2nd International Conference on Marketing (ICOM 2014), (pp. 92-100).

Rathnayake, T., \& Rathnayake, D. (2018). Facebook usage of Sri Lankan consumers: consumption perspective of social media. Arts and Social Sciences Journal. 
Samit, C. E., \& CAZACU, S. (2016). The attitudes and purchase intentions towards private label products, in the context of economic crisis: a study of Thessalonian consumers. Ecoforum Journal.

Sekaran, U., \& Bougie, R. (2016). Research methods for business: A skill building approach.

Statistics, D. o. (2018). Computer Literacy Statistics (First six months).

Susan Meyer. (2020). Evolving Ecommerce: 14 Trends Driving Online Retail In 2020. Retrieved from Ecommerce Research: https://www.bigcommerce.com/blog/ecommerce-trends/\#14-ecommercetrends-leading-the-way

Zeithaml, V. A. (1988). Consumer Perceptions of Price, Quality, and Value: A MeansEnd Model and Synthesis of Evidence. Journal of marketing. 